\title{
Analysing the characteristic features of a pre-monsoon thunderstorm event over Pune, India, using ground-based observations and WRF model
}

\author{
P P Leena ${ }^{1, *}$, G Pandithurai ${ }^{1}$, K Gayatri ${ }^{1}$, P Murugavel $^{1}$, R D Ruchith ${ }^{1,2}$, \\ S Sakharam ${ }^{1}$, K K Dani ${ }^{1}$, Chetana Patil ${ }^{3}$, T Dharmaraj ${ }^{1}$, M N Patil $^{1}$ \\ and THARA PRABHAKARAN ${ }^{1}$ \\ ${ }^{1}$ Indian Institute of Tropical Meteorology, Pune 411 008, India. \\ ${ }^{2}$ Department of Atmospheric Sciences, Cochin University of Science and Technology, Cochin, India. \\ ${ }^{3}$ Department of Atmospheric and Space Sciences, Savitribai Phule Pune University, Pune 411 00\%, India. \\ *Corresponding author.e-mail: leena@tropmet.res.in
}

MS received 17 May 2018; revised 14 September 2018; accepted 29 September 2018; published online 11 April 2019

In the present work, the characteristic features and factors contributed to the formation of a typical pre-monsoon thunderstorm that occurred over Pune has been studied using various ground-based observations, such as microwave radiometer profiler, wind lidar and surface eddy covariance flux measurements along with weather research and forecast (WRF) model. Initially, the thermodynamic state of atmosphere, variation in fluxes, as well as convective updrafts and downdrafts associated with the thunderstorm event, has been studied using ground-based observations. Thermodynamic indices derived from ground-based microwave radiometer observations showed significant variation before, during and after the development of thunderstorm such as smaller humidity index and higher values of total total index and $K$-index during the storm. Convective available potential energy (CAPE) and equivalent potential temperature have also shown an increase prior to the event. It is noted that sensible heat flux is higher than latent heat flux before the initiation of storm, however, the latent heat flux increased significantly during the storm. Wind lidar-derived vertical velocities showed strong variation i.e., exceeding $3 \mathrm{~m} \mathrm{~s}^{-1}$ during the event. Signatures of veering effect indicated the transport of moisture to higher levels was noticed from the altitude variability of wind vector. Ground observations suggested strong crosswind wind shear, convergence of moisture that originated at elevated levels in the boundary layer and enhancement of moist static energy in the elevated layer above the surface was pre-storm characteristics that conducive for the storm enhancement. Secondly, the capabilities of a WRF model in simulating the storm development, structure and evolution have been verified. The WRF model was able to recreate major features of the environment in which the storm was developed. The model output was compared with ground observations, which showed that the model has well captured the sensible heat and friction velocity as that of observation compared to mixing ratio and latent heat. It is observed that the water vapour variation in the model is having a lag, about an hour, with that of observations. The detailed analysis of

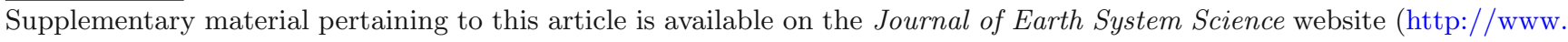
ias.ac.in/Journals/Journal_of_Earth_System_Science). 
model output did not show triggering of a thunderstorm as noted in the observation at the same location, which may be probably due to model bias in the moisture transport or moisture convergence was weaker in the model.

Keywords. Thunderstorm; ground-based observations; WRF model; dry-wet transition.

\section{Introduction}

Thunderstorms cause devastating consequences such as lightning, heavy precipitation, hail and wind gusts, hence causing difficulties to not only public life, but also in other activities such as satellite launch operations, air transport, etc. Thus, understanding the characteristic features of a thunderstorm, its thermodynamic structure, factors contributed to the formation, etc. are very important. Several studies have been carried out to understand the thunderstorm activity using observations such as radars, lightning network and even by using numerical models, i.e., WRF (weather research forecast). Interestingly, most of the studies in the literature are based on mid-latitude systems. This may be probably because for those regions the gust front plays an important role in determining the evolution of the storm (e.g., Weisman and Klemp 1982) and vertical wind shear needed to produce supercells are quiet less (e.g., Ulrike and Robert 2009). Over continental tropics, observations for the study of the genesis of storms are rare which may be possibly due to the difficulty in obtaining the vertical structure of the storms or difficult to forecast as the time span of these convective systems is about 20-30 min. Thus, understanding of their thermodynamic structure, especially in tropical regions, is very important.

Thunderstorm study was mainly carried out using techniques/observations such as radars (Leslie et al. 1977; Sen et al. 2010; Srivastava et al. 2010; Litta et al. 2012), radiosonde (Ravi et al. 1999; Basu and Mondal 2002; Chaudhari et al. 2010; Tajbakhsh et al. 2012; Pucik et al. 2015), lightning network (Dieter 2014), electric field mill (Pawar and Kamra 2009; Pawar et al. 2014) and numerical models like WRF (Litta and Mohanty 2008; Litta et al. 2012 and references there within), where the extrapolation of radar reflectivity echoes to forecast the location of convective storms was used widely. But the accuracy of these forecasts generally decreases rapidly during the first $30 \mathrm{~min}$ because of the very short lifetime of individual convective storms. Few studies (e.g., Browning 1980; Wilson and Mueller 1993; Wilson et al. 1998, etc.) have suggested that techniques for forecasting the initiation, growth and dissipation of convective storms are very essential for the forecast periods beyond $\sim 20 \mathrm{~min}$. Numerical weather prediction (NWP) models have difficulty in representing these storms and their vertical structure since the vertical structure is decided by the interaction between the environmental shear and microphysical interactions. Apart from this, many statistical techniques (e.g., Reap 1994; Lambert et al. 2005, etc.) were also developed to forecast thunderstorm. Rajeevan et al. (2012) developed a statistical model based on binary logistic regression for predicting the probability of lightning occurrence over southeast India using the perfect prognostic method (PPM). Though many studies were carried out using various techniques/observations, the prediction of severe convective events is still a difficult process which may be mainly because of (i) lack of observations of the initial state or (ii) relative coarse resolution.

We know that continuous observations are required to study the temporal evolution of these convective activities which in turn will help in the prediction of the same. Over the Indian region, the thunderstorm-related studies were mainly carried out using observations such as radiosonde (Ravi et al. 1999; Basu and Mondal 2002; Chaudhari et al. 2010 and references there within), weather radars (Mukhopadhayay et al. 2009; Srivastava et al. 2010; Sen et al. 2010; Roy Bhowmik et al. 2011; Litta et al. 2012; Suresh 2012), WRF models (Litta and Mohanty 2008; Litta et al. 2012), field mill (Madhulatha et al. 2013; Pawar et al. 2014), etc. Along with these well-established observations, in recent years, the ground-based remote sensing instrument such as microwave radiometers or radiometer profiler (MWR or MWRP) has been used for the studying convective activity as it provides unique opportunity to monitor the thermodynamic state continuously at a location (Chan 2009; Chan and Hon 2011, etc.). Also, over 
the Indian region, observations from MWR have been used for the study of thunderstorm events (Madhulatha et al. 2013; Bhate et al. 2016; Leena et al. 2016, etc.). Although earlier studies/ observations record various storm indices, which are useful parameters in discerning the formation, strength and duration of the storms, but further information on the fluxes associated, structural characteristics, etc. is missing. This information can be provided by several other observational systems such as eddy covariance system, wind lidar, etc. In general, the main limitations of earlier studies were information on severe convective events was retrieved (i) either by using single ground observational source or (ii) by combining single observation with the WRF model. This may be a major reason for incomplete information on thunderstorm activity, especially over the tropical region, which can be resolved to the maximum by carrying out studies by combining several ground observations.

Indian Institute of Tropical Meteorology (IITM) located at Pune $\left(73.86^{\circ} \mathrm{E} ; 18.5^{\circ} \mathrm{N}\right)$ has several co-located ground-based measurements such as microwave radiometer, eddy covariance system, wind lidar, etc. The combination of these ground observations in a single analysis can help to understand the conditions that favoured storm development, its duration and intensity along with the fluxes associated, structural characteristics, etc., which is mainly lacking in most of the earlier studies carried out using the single observational source. Considering all these, the main objectives of the present study are (i) to analyse the thermodynamic state of atmosphere, variation in fluxes and convective updraft and downdraft associated with the thunderstorm occurred on 24 April 2011 over Pune using these groundbased observations and (ii) to verify whether the WRF model is able to recreate major features of the storm or environment in which the storm developed and (iii) comparing the output of WRF model with ground observations. Overall, this study will show the importance of combining several co-located ground-based observations for understanding thunderstorms. Also, the present analysis will help to provide a better understanding of the factors that contributed to the formation of thunderstorms and also to investigate the capability of the mesoscale model in simulating the storm development, structure and evolution. It is to be noted that we have selected particular pre-monsoon thunderstorm because all the ground-based instruments mentioned were in operation during that event.

\section{Synoptic condition and study region}

Over the Indian region, thunderstorms are typically observed during the pre-monsoon season (March-April-May) which is mainly a hot weather period (Tyagi and Vissa 2013). In the year 2011, during this season according to India Meteorological Department (IMD) and Daily Weather Report (IDWR) (ftp://intranet.tropmet.res.in/IMD-wea ther-reports/), it is seen on 23 April 2011 that there is a trough/wind discontinuity at $0.9 \mathrm{~km}$ above sea level (a.s.l.) from east Rajasthan to Lakshadweep area persists across west Madhya Pradesh, Marathwada, south Madhya Maharashtra, north interior Karnataka and coastal Karnataka with an embedded cyclonic circulation over east Rajasthan and neighbourhood. Further on 24th April, the trough/wind discontinuity at $0.9 \mathrm{~km}$ a.s.l. was seen running from east Rajasthan to Kerala, Madhya Maharashtra and other places with the embedded cyclonic circulation over east Rajasthan and neighbourhood. On the next day i.e., 25th the same discontinuity at $0.9 \mathrm{~km}$ a.s.l. seems to be running from east Rajasthan to south Tamil Nadu across Madhya Maharashtra with an embedded cyclonic circulation over east Rajasthan and neighbourhood. During these days, Pune weather remained dry (very hot) with a temperature of $38^{\circ} \mathrm{C}$. According to the IDWR report, Pune region experienced a squall at 16:10 IST on 24th April from northwest to southeast direction with a wind speed of $68 \mathrm{kmph}$ and fall in temperature by $14^{\circ} \mathrm{C}$ with the rise in pressure by $2 \mathrm{hPa}$. A report based on the observation taken at 08:30 IST of 25 April 2011 has shown the rainfall of $25.6 \mathrm{~mm}$. This was the recorded rainfall from rain gauge in automatic weather station over Pune for past $24 \mathrm{hr}$. Hence, the present study considered this case of thunderstorm, i.e., occurred on 24 April 2011 over Pune. Pune $\left(73.86^{\circ} \mathrm{E}\right.$ and $\left.18.5^{\circ} \mathrm{N}\right)$ is situated at the lee side of Western Ghats in a valley and at an elevation of $570 \mathrm{~m}$ above mean sea level. Figure 1 shows the terrain map representing the study region. The synoptic condition described for the mentioned case suggested a dry to wet transition with a region extending from Pune to central India (see supplementary figure S1, showing the contrasting dry-wet regime). It is also seen from supplementary figure S1 that all the storms close to the study region were formed along the convergence zone. 


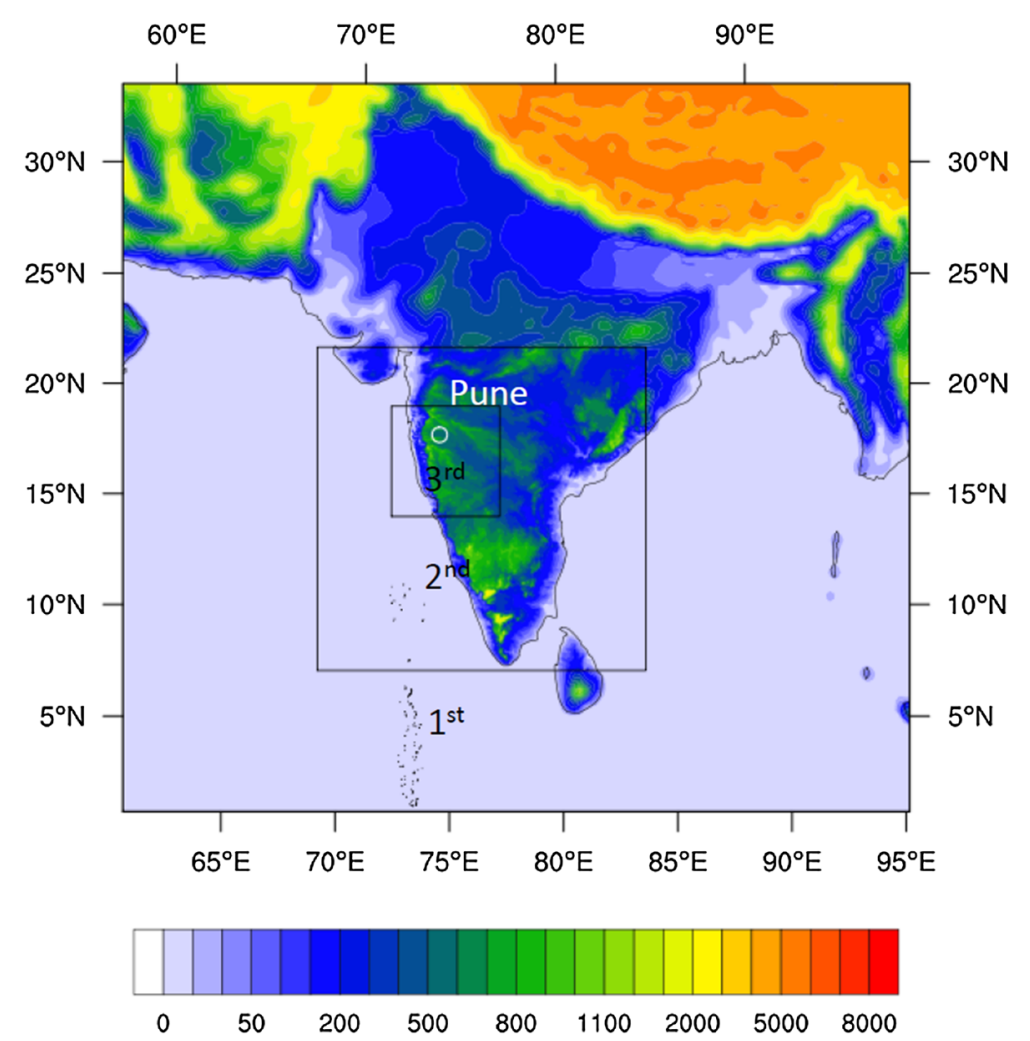

Figure 1. Topographic height in model domains 1-3 (circle in the figure shows Pune).

\section{Data used}

As we have mentioned before, a study carried out by combining several co-located ground-based observations can bring an in-depth understanding of severe convective activity which is not possible with a single observational source. Thus, for the fulfilment of the objective, we have used various co-located ground-based observations such as microwave radiometer profiler, wind lidar and surface eddy covariance flux measurements along with the WRF model. A combination of these observations can provide information on the conditions that favoured storm development, fluxes associated, structural characteristics, etc., in a single study. Details of the observations used are given below.

\subsection{Microwave radiometer}

Ground-based radiometer (MWR) used for the above-mentioned case is MP-3000A (manufactured by Radiometrics Corporation, USA), a 35-channel temperature, water vapour and liquid water profile. Temperature profiles can be obtained by measuring the radiation intensity, or brightness temperature, at points along the side of the oxygen absorption band at $60 \mathrm{GHz}$. Similarly, water vapour profiles can be obtained by observing the intensity and shape of emission from pressure broadened water vapour lines. The line near $22 \mathrm{GHz}$ is suitable for ground-based profiling in relatively moist areas. MWR retrieves temperature and relative humidity profiles with a temporal resolution of 2 min and spatially with a resolution as follows: up to $500 \mathrm{~m}$ with $50 \mathrm{~m}, 500 \mathrm{~m}$ to $2 \mathrm{~km}$ with $100 \mathrm{~m}$ and $2-10 \mathrm{~km}$ with $250 \mathrm{~m}$. For the present study, the entire data set has been interpolated to height intervals of $100 \mathrm{~m}$ resolution and taken the hourly average. Apart from obtaining the vertical profiles, the radiometer also provides surface parameters, i.e., temperature and relative humidity, integrated products such as vapour and liquid and also cloud base height (more details in https://doi.org/10.12898/ES0702FR). Hence, the observations from MWR have been used to obtain the thermodynamic state of atmosphere before, during and after the development of a thunderstorm.

\subsection{Wind lidar}

Doppler wind profiler at Pune is operating at $1.54 \mu \mathrm{m}$ wavelength by using Doppler beam swinging (DBS) method with off zenith angle of $15^{\circ}$ 
towards north, east, south and west. The scattered signal Doppler shift and the wind speed along the line of sight are mainly determined from the backscattered laser radiation obtained from the atmosphere. Mainly the backscattering from the atmosphere is obtained by using aerosols as 'tracers', basically assuming that the movement of aerosols is along with the wind. An important feature of this laser radar is that it has the capability to give the $3 \mathrm{D}$ components of wind in the troposphere starting from 100 to about $12,000 \mathrm{~m}$ depending on the availability of the sufficient number of scatterers. Apart from that, this can continuously profile the atmosphere with a spatial resolution of $50 \mathrm{~m}$ and temporal of $30 \mathrm{~s}$. More details can be obtained from Raj Ernest et al. (2012) and Ruchith et al. (2014). Hence, the wind information obtained from wind lidar has been used for studying the convective updrafts and downdrafts.

\subsection{Eddy covariance system}

Eddy covariance sensors of eddy covariance system constitute an ultrasonic anemometer-thermometer (Wind Master Pro, Gill Instruments Ltd., UK) and co-located $\mathrm{CO}_{2} / \mathrm{H}_{2} \mathrm{O}$ open-path infra-red gas analyser (Li-7500A, LICOR Inc., USA). Measurements were carried out for $6 \mathrm{~m}$ with a sampling rate of $10 \mathrm{~Hz}$. The method introduced by Vickers and Mahrt (1997) was used for the removal of spikes in the data. Then a two-dimensional coordinate rotation was carried out (more details in Kaimal and Finnigan 1994) to make the mean vertical velocity zero and the axis is aligned with the direction of the mean wind. The observations from these sensors such as longitudinal, lateral, vertical components of winds, virtual air temperature, water vapour concentration, etc., were used for the estimation of sensible and latent heat, friction velocity, turbulent kinetic energy and vertical flux of turbulent kinetic energy. More details on the calculation of these parameters can be obtained from Patil et al. (2014).

\subsection{Weather research and forecasting model (WRF V3.4)}

The Advanced Research Weather (ARW) forecasting model, i.e., WRF V3.4 was used for the present case simulation which was configured with three two-way nested domains (27, 5.4 and $1.08 \mathrm{~km}$ resolution). Model domains are mentioned in figure 1.
The model has total of 49 levels, the lowest model level is kept at approximately $7 \mathrm{~m}$ above the surface and the top layer was kept at $19 \mathrm{~km}$. Yonsei University (YSU) non-local PBL scheme was used for boundary layer parameterisation which was coupled with the Monin Obukhov (MO) similarity scheme for the surface layer and Noah land surface scheme (Chen and Dudhia 2001) using the updated MODerate resolution imaging spectroradiometer (MODIS) land use dataset. The non-local PBL scheme is more appropriate since the convective boundary layer such as the one described over Pune is indeed characterised by deep convective thermals, rolls and have wave interactions. The innermost domain has a cloud permitting/cloud resolving model whereas the second and outer domain is parameterised with the Kain and Fritsch cloud scheme. The WRF double moment (WDM-6) cloud microphysics scheme was used with modified boundary conditions. In order to damp the vertically propagating waves in the upper layers, we have used the new parameterisation of Klemp et al. (2008). The model is initialised with final reanalysis products (FNL) from the National Center for Atmospheric Research (NCAR) and outer boundary updates are made every $6 \mathrm{hr}$. The initial time for simulations is at 04 UTC of 24 April 2011. Hourly model output is used in the analysis. More details can be obtained from Prabha et al. (2011) where a similar configuration was used.

\section{Results and discussion}

\subsection{Thermodynamic state and variation in thermodynamic indices}

Thermodynamic state of atmosphere associated with the thunderstorm event is examined initially by analysing the temporal variation in basic atmospheric parameters obtained from MWR observations (figure 2). It is seen that during the day time the temperature (figure 2a) was greater than $305 \mathrm{~K}$ and RH was less than $30 \%$. After 14:30 IST, there is an increase in the $\mathrm{RH}$ and integrated water vapour/cloud water (total column of water vapour/ liquid from the ground to $10 \mathrm{~km}$, figure $2 \mathrm{~b}$ ). The temporal variability of cloud base height $(\mathrm{CBH}$, figure 2c) has shown that there is a presence of thin cirrus layers above $8 \mathrm{~km}$. It is also seen that there is no cloud cover until the initiation of storm, i.e., after 15:30 IST. The gradual moistening of the lower layers (below $2 \mathrm{~km}$ ) and mid layer (within 

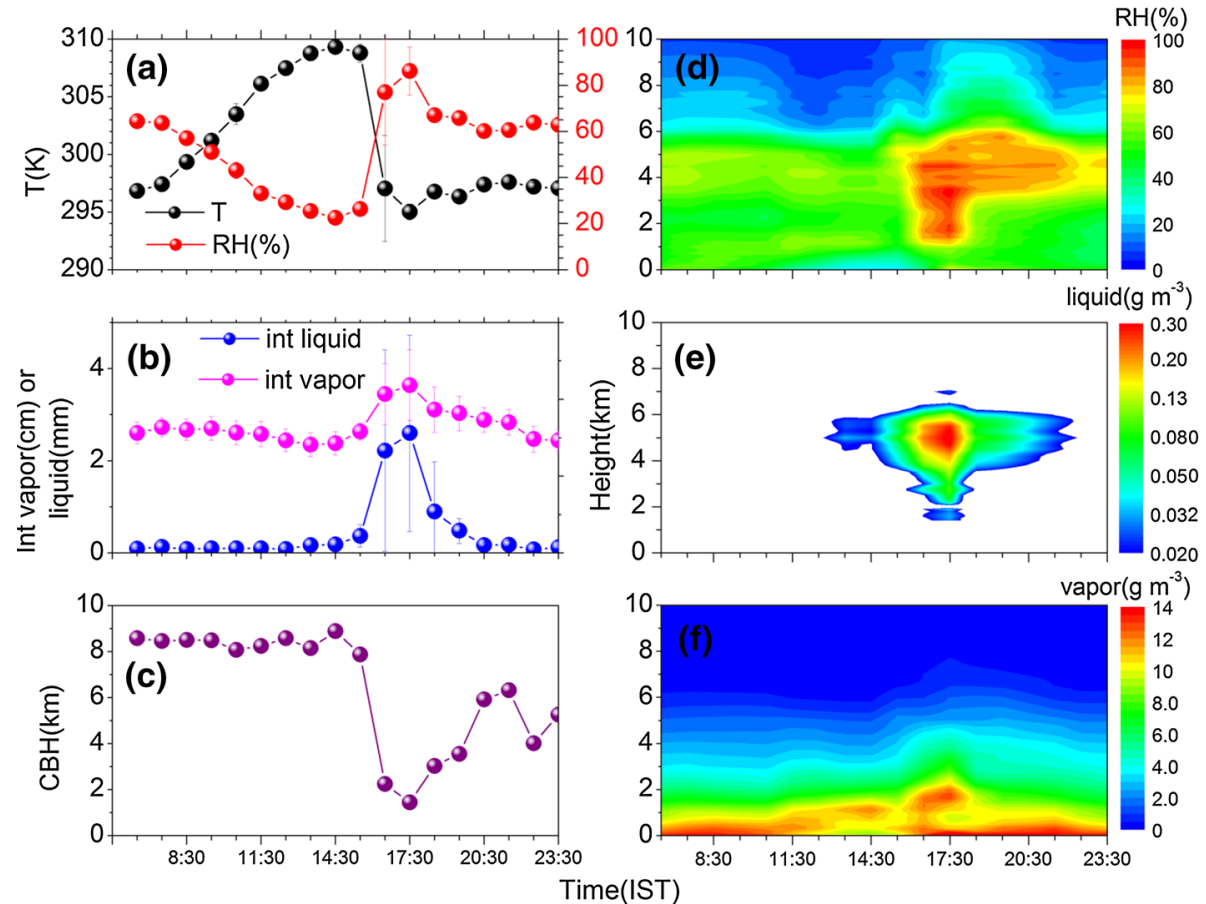

Figure 2. Line plot (left panel) showing diurnal variation of (a) temperature and RH, (b) integrated vapour and liquid, (c) cloud base height (vertical lines indicate the standard deviation) and contour plot (right panel) showing time-height cross-section of (d) RH, (e) liquid and (f) vapour obtained from MWR.

2-6 km) is noted with relative humidity exceeding $70 \%$ (figure $2 \mathrm{~d}$ ). Water vapour mixing ratio in the lower layers shows a noticeable increase before the storm (figure 2f). During the storm, the maximum cloud water is noted between 2 and $6 \mathrm{~km}$ layers (figure 2e). The storm depth was sustained for more than an hour and storm lasted for almost $2 \mathrm{hr}$. The storm structure is seen with vertical development and after 18:30 IST, the storm is identified with a cloud layer between 3 and $6 \mathrm{~km}$. This could be associated with the outflow and the stratiform part of the convection which lingered for several hours after the storm. It is noted that there is a significant increase in the $\mathrm{RH}$ at higher elevations after the storm, as a result of moistening in the stratiform part of the storm and also mixing ratio profiles indeed showed tilting nature with height and time.

For a better understanding of temperature variability, stability and moisture content of the atmosphere, we have analysed various thermodynamic indices which will be even helpful to study the development of the storm. Temporal variation of six different thermodynamic indices, i.e., humidity index $(\mathrm{HI}), K$-index $(\mathrm{KI})$, total total index (TTI) and mean $\mathrm{RH}_{940-850 \mathrm{hPa}}, \mathrm{CAPE}$ and CINE (more details about the indices/calculations in Venkat Ratnam et al. 2013; Madhulatha et al.
2013; Leena et al. 2015, 2016), associated with the thunderstorms, is shown in figure 3. Apart from these six indices, we have also estimated the equivalent potential temperature which is needed to explain the moist static energy of the atmosphere (figure 3f). It is to be noted that the thermodynamic indices and equivalent potential temperature represented in the figure are within $\pm 06 \mathrm{hr}$ of the occurrence of the storm. It is seen from the figure that HI, KI and TTI (figure $3 \mathrm{a}-\mathrm{c}$ ) have a significant increase about an hour before the storm. HI is an important parameter which quantifies the potentially available water vapour, KI considers both the moisture availability at $850 \mathrm{mb}$ and the moist layer thickness, i.e., at $700 \mathrm{mb}$ whereas TTI mainly includes the moisture availability at $850 \mathrm{mb}$. It is seen that the temporal variation of $\mathrm{HI}$ showed very low value $\left(<5^{\circ} \mathrm{C}\right)$ during the event which may be due to the decrease in dew point depression as relative humidity increases. Higher values of KI and TTI during the event not only confirm the presence of high moisture content, i.e., low-level moisture might have reached up to $850 \mathrm{mb}$, but also suggested the presence of low-level clouds such as cumulus clouds. Smaller HI and higher KI and TTI represent an atmospheric potential for thunderstorms to occur. Apart from this, 

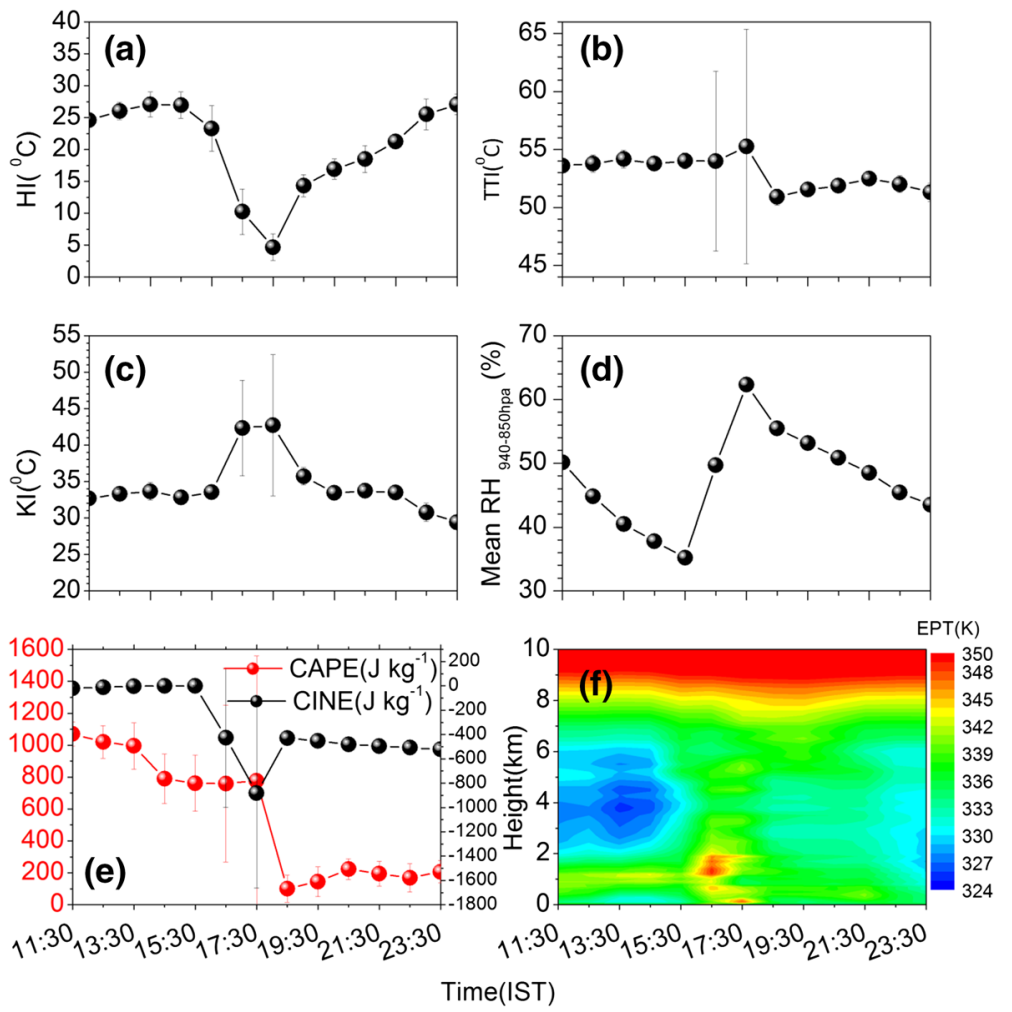

Figure 3. Temporal variation of (a) HI, (b) TTI, (c) KI, (d) mean $\mathrm{RH}_{940-850} \mathrm{hPa}$, (e) CAPE and CINE (vertical lines indicate the standard deviation) and (f) time-height (AGL) cross-section of equivalent potential temperature within \pm 6 hr of the occurrence of storm.

mean RH (figure 3d), which is important for the genesis of the storm and also provides information on the role of moisture in convective inhibition, has shown significant change during the event and even $1 \mathrm{hr}$ prior to it. It is noticed that there is a $\sim 20 \%$ increase of $\mathrm{RH}$ from the surface to boundary layer during the storm. In the case of CAPE (figure 3e), it is observed that the instability has started $\sim 6 \mathrm{hr}$ before the storm where the CAPE has gone above $1000 \mathrm{~J} \mathrm{~kg}^{-1}$, whereas CINE has not shown much variation before $6 \mathrm{hr}$. The high value of KI and CAPE indicates that the storm was formed due to strong vertical uplift of moist air. This is even seen from the equivalent potential temperature (figure 3f), where moisture transport in the middle layer was noted. It is also noticed that the equivalent potential temperature has increased prior to the event suggesting that the moist static energy has started increasing before the initiation of a thunderstorm.

We have even compared the present MWR observations with other reported pre-monsoon convective events from different parts of the world. It is seen that the study by Chan (2009) over Hong Kong, China, has reported low $\mathrm{CBH}$, high $\mathrm{RH}$, liquid and KI during a convective event. Similarly,

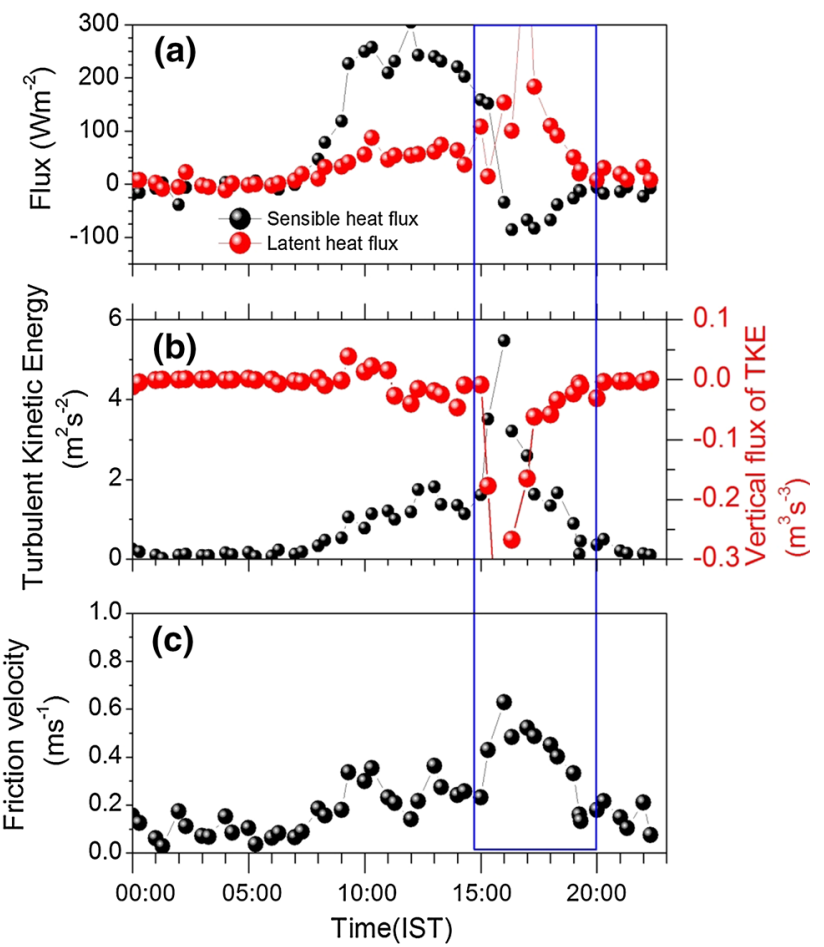

Figure 4. Temporal variation of (a) sensible heat flux and latent heat flux, (b) turbulent kinetic energy (TKE) and vertical flux of TKE and (c) friction velocity estimated from ECS (blue box highlight time when the thunderstorm happen). 

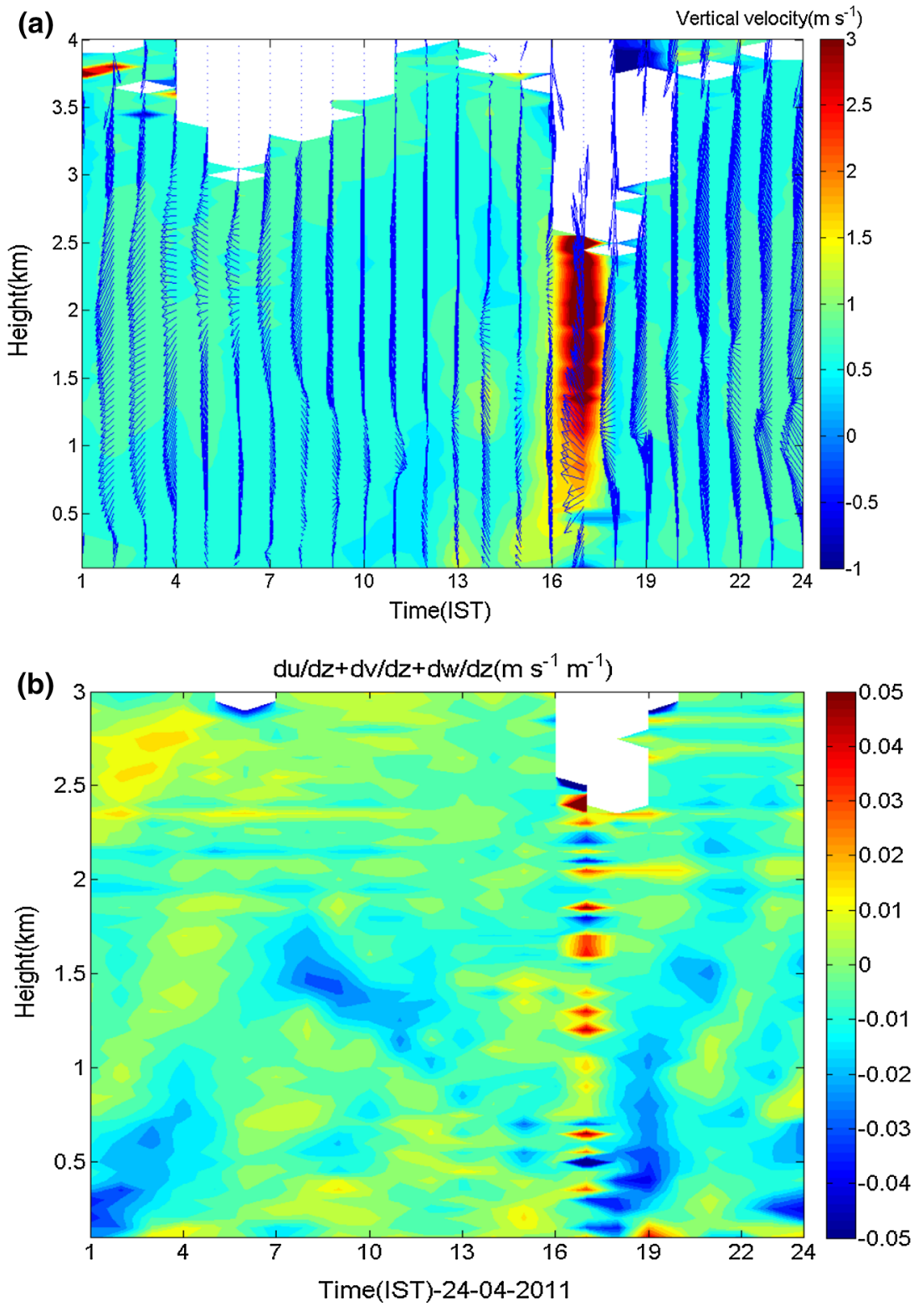

Figure 5. Time-height cross-section of (a) vertical wind speed along with wind direction and (b) wind shear obtained from wind lidar observation.

high vapour density, liquid, CAPE, KI and low HI were observed over Gadanki, an Indian tropical station by Madhulatha et al. (2013) during a pre-monsoon convective event. On comparing the present results with these studies, it is seen that $\mathrm{CBH}$, stability indices such as KI, HI CAPE, etc., showed similar temporal variation with slight changes in the reported values. The vertical profiles of RH, liquid, vapour, etc., also showed similar variation. Hence, the comparison has shown (i) the robustness of MWR for the study of severe convective event and (ii) that the analysed thermodynamic indices are very important to understand the stability of atmosphere during convective events.

\subsection{Variation associated with fluxes, vertical wind and wind shear}

It is clear from the previous section that thermodynamic indices estimated from MWR observations exhibit significant temporal variation during the thunderstorm activity. Not only the thermodynamic indices but also the information on fluxes associated, variability in vertical wind and shear is equally important to understand the thunderstorm activity. Thus, in this section, we are discussing the variation of fluxes estimated from the eddy covariance system and vertical wind obtained from wind lidar. We have calculated sensible heat and latent heat flux along with friction velocity, turbulent 

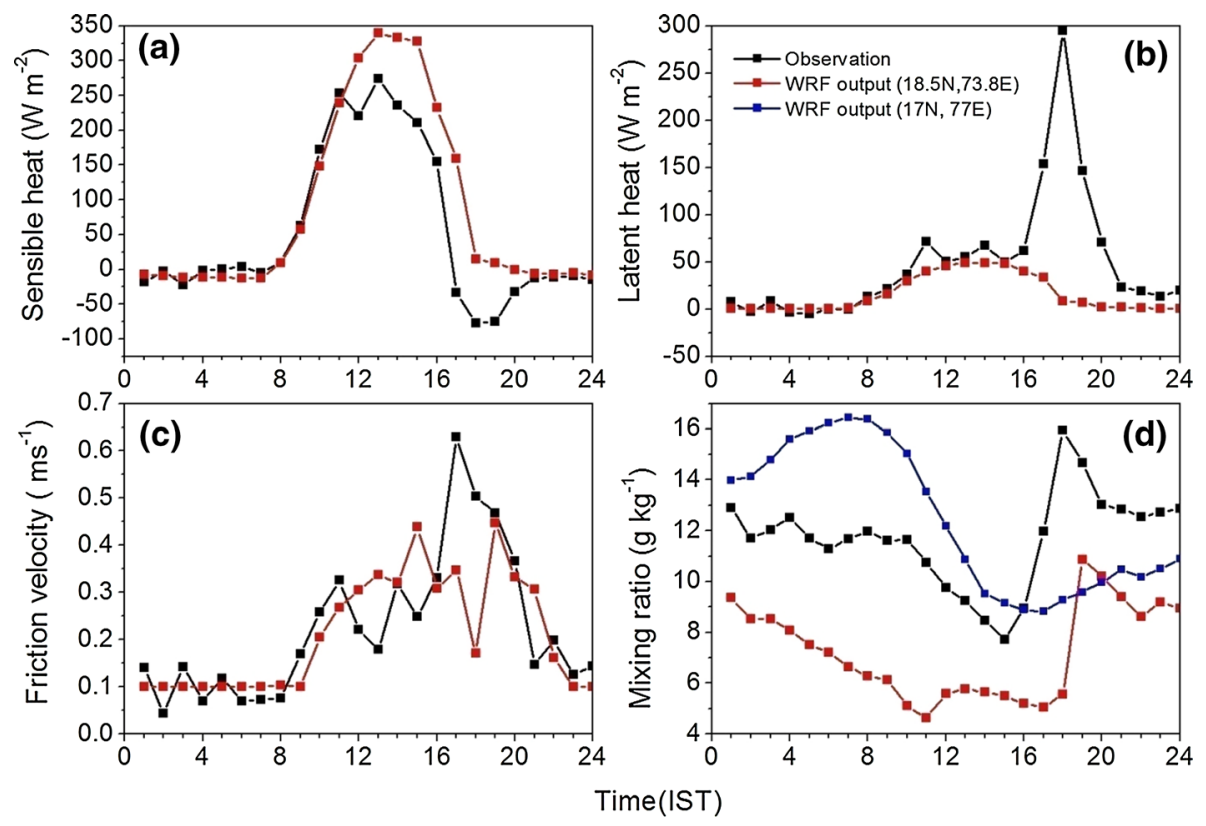

Figure 6. Comparison between WRF model output and observation for (a) sensible heat flux ( $\left.\mathrm{W} \mathrm{m}^{-2}\right)$, (b) latent heat flux $\left(\mathrm{W} \mathrm{m}^{-2}\right),(\mathbf{c})$ friction velocity and (d) mixing ratio. (Mixing ratio from WRF output for Pune (red line) and new location (blue line) has shown.)

kinetic energy (TKE) and vertical flux of TKE (figure 4). These parameters are important to describe the surface-atmosphere interactions before, during and after the storm. It is clearly seen from figure 4(a) that the sensible heat flux is higher than the latent heat flux before the initiation of the storm, however, the latent heat flux increased significantly during the storm. This suggests that the atmosphere was initially dry and during the thunderstorm, the atmosphere has become moist. Higher latent heat may be partly due to the evaporation of falling precipitation. The variation in latent and sensible heat flux during the thunderstorm was similar to that reported by Tyagi et al. (2012). Their study has shown the variation with the same parameters during thunderstorm days over Ranchi, India, which is obtained from fast response sensors mounted over a $32 \mathrm{~m}$ micrometeorological tower. It is also seen that the reported values were almost similar or within the range of the present study. The turbulent kinetic energy shown in figure 4(b) has increased significantly during and even prior to the storm. The estimated vertical flux of turbulent kinetic energy has reduced at the time when a thunderstorm occurred, suggesting that not only the energy has increased but there was strong downdraft near the surface which transported the turbulent kinetic energy. The changes in the turbulent kinetic energy were noted $2-3 \mathrm{hr}$ before the thunderstorm initiation.
Apart from this, the friction velocity (figure 4c) has also started increasing prior to the event up to $0.6 \mathrm{~m} \mathrm{~s}^{-1}$ suggesting the surface stress has started increasing. The friction velocity remained high after the storm, indicating sustained turbulence and mixing after the storm.

Another most important parameter analysed during the severe convective event is updraft and downdraft. For the present study, the convective updrafts and downdrafts associated with this thunderstorm have been derived from wind lidar (figure 5a). It is observed that there were strong vertical velocities exceeding $3 \mathrm{~m} \mathrm{~s}^{-1}$ at the time of the event. Not only during the event, but the increase in vertical velocity was noted even $\sim 4 \mathrm{hr}$ before the storm, in the lower levels associated with the convective boundary layer. Interestingly, it is observed that when a thunderstorm occurred, the vertical wind increased at several heights above the surface simultaneously and there is a clockwise rotation in wind vector, superimposed over the vertical velocity, showing the veering effect indicating the significant transport of moisture into the area. The increase in vertical velocity during the thunderstorm event has even reported by Rajeevan et al. (2010) over a tropical station Gadanki, India, using MST (mesosphere-stratosphere-troposphere) radar observation. They have seen an increase in velocity with respect to height with values going up to 

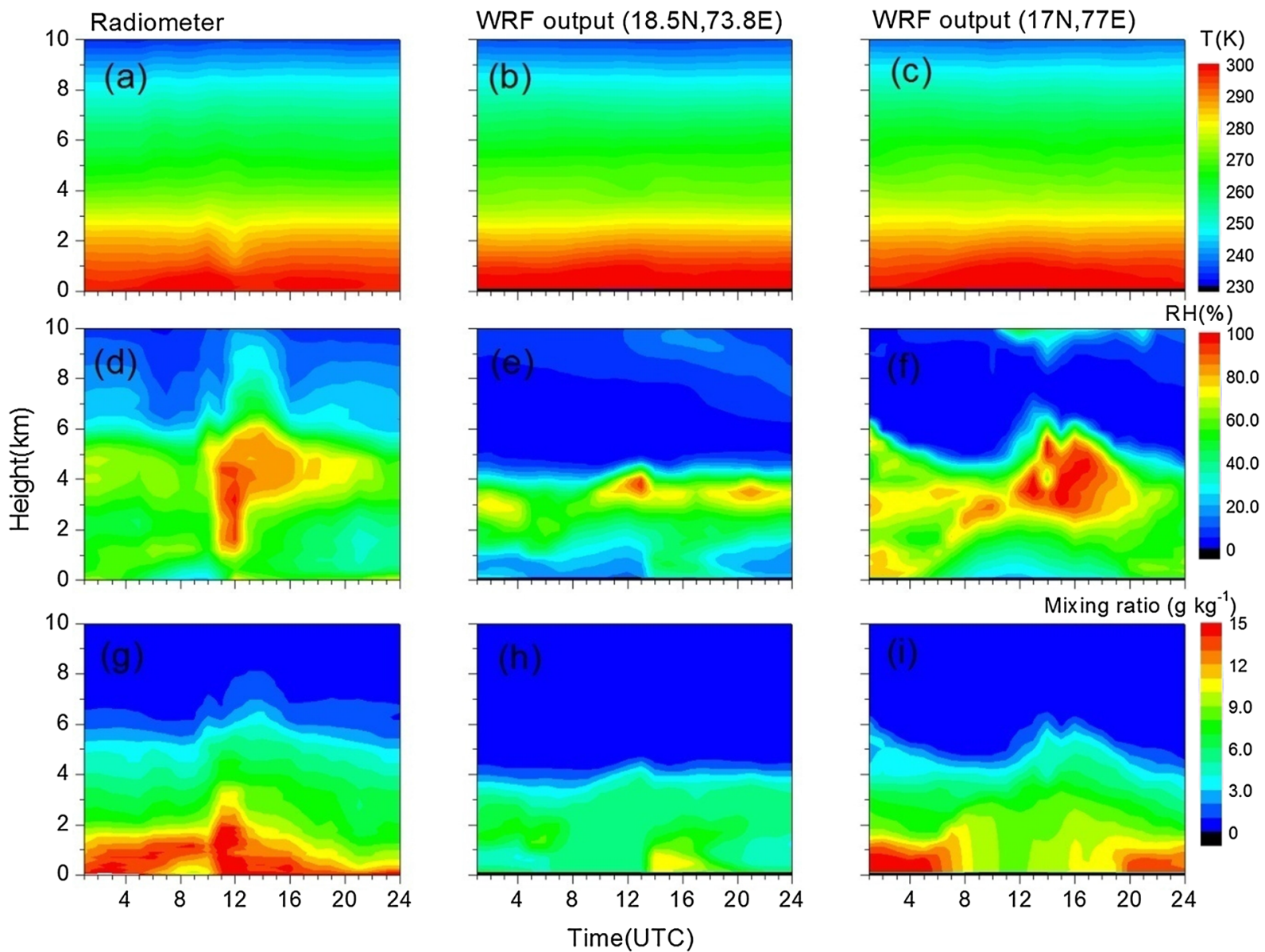

Figure 7. Comparison between WRF model output (for two locations) and observation for vertical profiles of (a-c) temperature, (d-f) $\mathrm{RH},(\mathbf{g}-\mathbf{i})$ mixing ratio.

$4 \mathrm{~m} / \mathrm{s}$. It is also noticed from the figure that the horizontal wind speed has also increased and a jet is re-established. Figure 5(b) shows the wind shear estimated from wind lidar data. It is seen that wind shear started increasing at higher levels (i.e., above $2 \mathrm{~km}$ ) in the morning hours and gradually increased at lower levels (especially below $1 \mathrm{~km}$ ) in association with the initiation of the storm. The boundary layer wind shear was high during the initiation of the storm, mainly contributed by the crosswind component. The wind shear also showed a significant change with height, indicating the positive shear near the surface and negative shear above. During the storm, the wind shear was mainly contributed by the vertical component of velocity. The crosswind shear had increased after the storm and high wind shear has propagated to higher levels and lasted for $2 \mathrm{hr}$. These observations suggest that the boundary layer wind shear was instrumental for the initiation of the storm. The friction velocity illustrated earlier in figure 4 also indicated enhancements during the storm and peaked after the initiation of the storm.

\subsection{WRF simulation and comparison with observations}

As a first step, we have compared the WRF model output with ground observations in order to verify whether the model is capturing the features of the event and also to get further information on the regional scale conditions contributed to the thunderstorm event. From the variation of surface products (figure 6), it is observed that the model has well captured the sensible heat (figure 6a) and friction velocity (figure 6c) as that of observation compared to mixing ratio and latent heat (figure $6 \mathrm{~b}$ and $\mathrm{d}$ ). Vertical profiles (figure 7) of temperature, $\mathrm{RH}$ and mixing ratio from model and radiometer were also compared and showed similar features but with a time lag (nearly an hour lag). Temporal variations of temperature profiles (figure $7 \mathrm{a}-\mathrm{c}$ ) did not provide much information but we could find that both $\mathrm{RH}$ (figure $7 \mathrm{~d}-\mathrm{f}$ ) and mixing ratio (figure $7 \mathrm{~g}-\mathrm{i}$ ) of WRF output have shown similar features as that of observations. It is observed that the water vapour variation in the model is having 

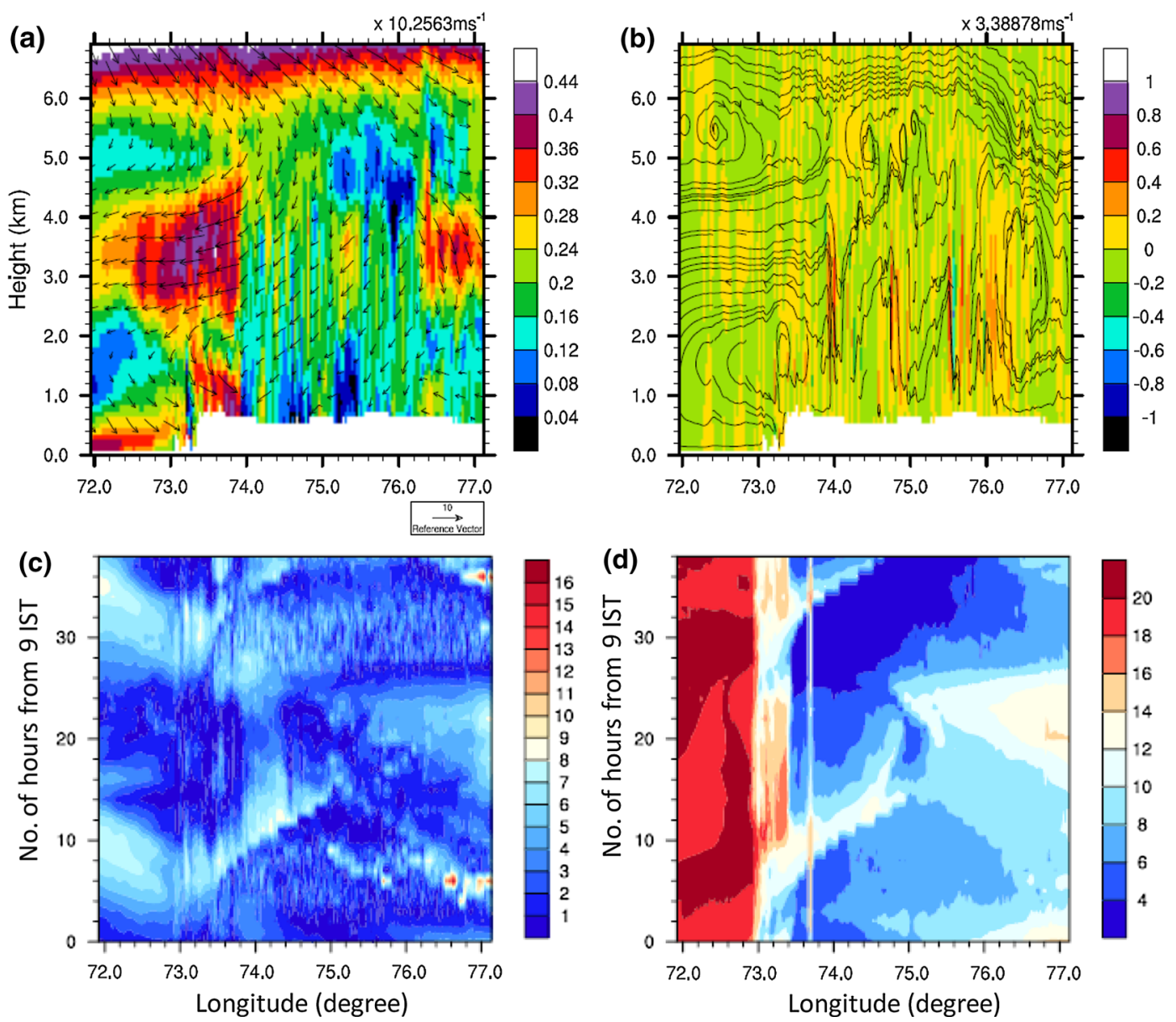

Figure 8. Longitude-height cross-section (along Pune latitude) of (a) horizontal wind speed and direction, (b) vertical velocity at 17:00 IST. The longitude-time plot of (c) surface wind speed and (d) water vapour mixing ratio (number at the top corner of the plot is the maximum value from the model and the colour scale is normalised with the maximum value).

a lag with that of observations, but the moistening of the mid-layer is clearly seen in both. Similar features have been observed in mixing ratio also, but the vertical extent of water vapour is more than $5 \mathrm{~km}$ in observations. The time lags in the model and observations are probably because it is apparent that the moisture convergence was weaker in the model than in the observations.

The observations alone cannot give a spatial picture of the evolution of the thunderstorm. So for verifying the evolution of the activity developed thunderstorm, we have taken the longitudeheight cross-section (along Pune latitude) of wind speed/direction information from the model (figure $8 \mathrm{a}$ and $\mathrm{b}$ ). It is visible from the figure that multiple jets are present over the western sector of the study region. The longitudinally aligned circulation in the lower $3 \mathrm{~km}$ with descending branch over the Arabian Sea and the low-level convergence from the Arabian Sea is evident. Arrows represented in the figure show the resultant wind direction. The strong vertical motions extend 4-5 km and are noticed in the regions of weaker horizontal winds (figure 8b). Figure 8(c and d) shows the time-longitude variation of wind speed and water vapour mixing ratio along Pune latitude. The propagation of stronger winds inland (figure 8c) and associated increase in water vapour mixing ratio are noticed (figure $8 \mathrm{~d}$ ) as the day progresses. It is to be noted that the model did not show triggering of a thunderstorm, as seen in the observation at the same location, however, the model formed thunderstorms further south and also west of the location, even with a spatial resolution of $1.08 \mathrm{~km}$. It is apparent that the moisture convergence was weaker in the model than in the observations (already illustrated in figure $6(\mathrm{~d})$, where the surface-level mixing ratio at Pune and the location (blue line in the figure) where a thunderstorm was spotted are presented and also illustrated in figure 7 by the comparison of water vapour mixing ratio). 

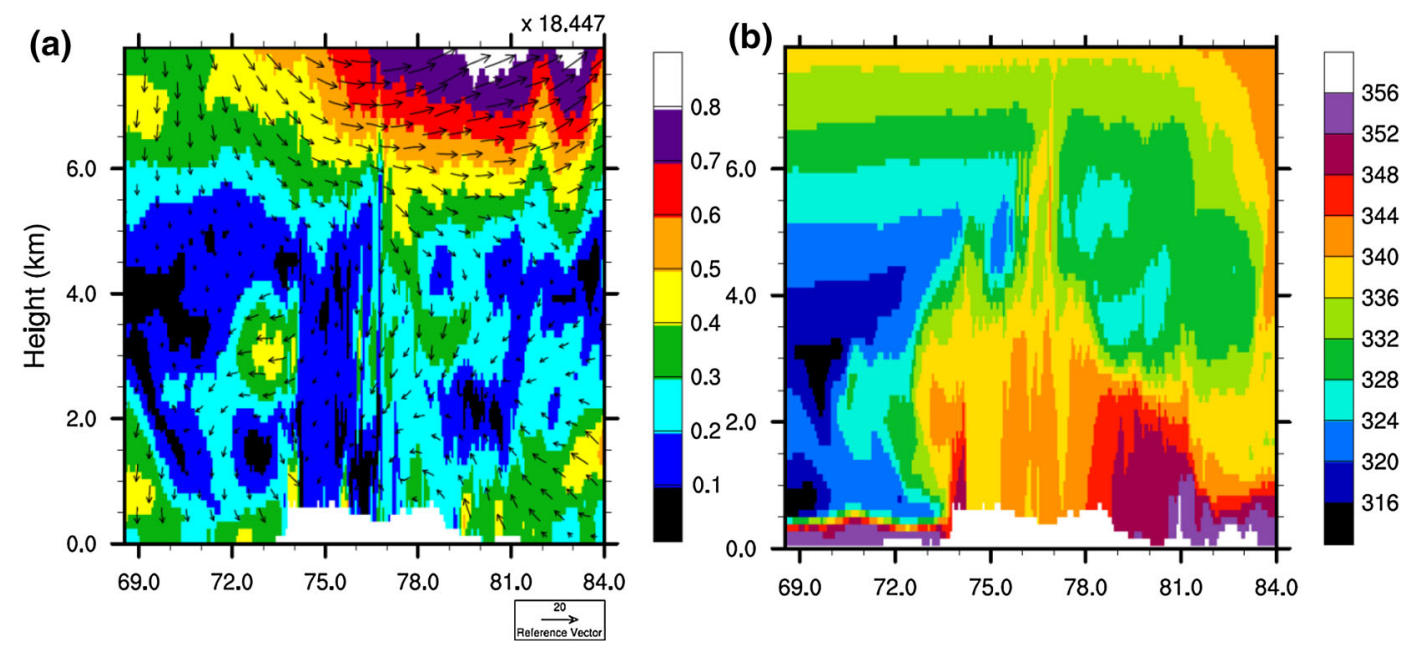

Figure 9. Longitude-height cross-section (from the second domain) of along the latitude of $17^{\circ} \mathrm{N}$ (where a thunderstorm was spotted at the same time as in the observations) (a) wind speed (maximum wind speed is $18.4 \mathrm{~m} \mathrm{~s}^{-1}$ ) and (b) equivalent potential temperature (number at the top corner of the plot is the maximum value from the model and the colour scale is normalised with the maximum value).

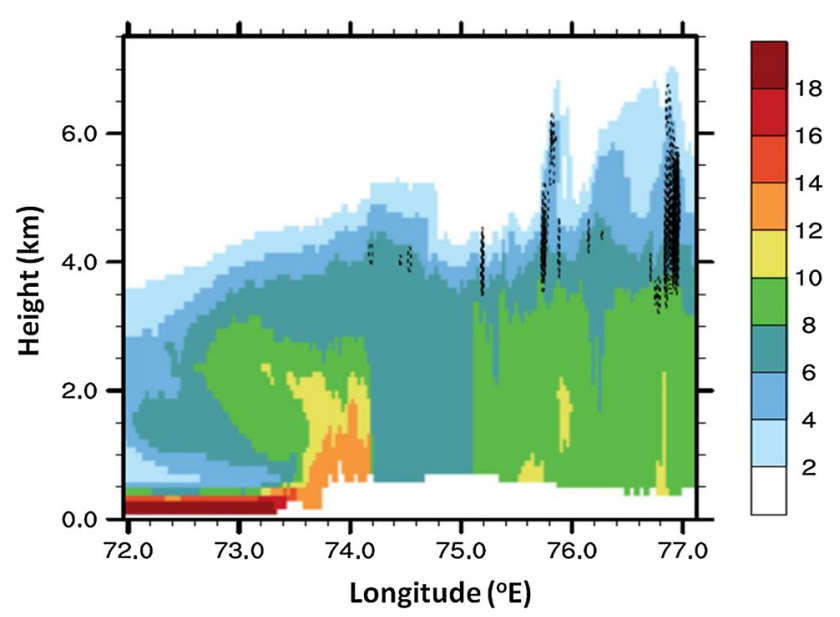

Figure 10. Vertical transect along $17^{\circ} \mathrm{N}$ (from the third domain) of cloud liquid water (shown with black contours) and water vapour mixing ratio $\left(\mathrm{g} \mathrm{kg}^{-1}\right.$; colour contours).

The instabilities formed in the vertical were not strong enough to penetrate higher levels and increase the moist static energy to those levels as illustrated in figure 8(b). As mentioned above, with the second domain $(5.4 \mathrm{~km})$ we could see that the thunderstorm formed further south-east of Pune. In order to illustrate the characteristics of that thunderstorm that is developed in the model, we have presented the wind speed (figure 9a) and equivalent potential temperature (figure 9b) from the second domain along the latitude of $17^{\circ} \mathrm{N}$, where a thunderstorm was spotted (figure 9). A thunderstorm was noted at the longitude of $76^{\circ} \mathrm{E}$ with northeasterly winds in the layers above $2 \mathrm{~km}$ and southeasterlies below that layer (like in the observations with wind lidar). The high equivalent potential temperature is seen up to an altitude of $7 \mathrm{~km}$. There are also weak winds in the western sector of the storm. The strong winds together with the inversion strength above $7 \mathrm{~km}$ restricted the depth of the storm. It is to be noted that this storm is situated nearly $150 \mathrm{~km}$ southeast of Pune. The general features of the storm in the model are similar to that of the storm observed over Pune. As indicated in the figures, the moist static energy across the convergence zone is quite variable and the vertical and horizontal variation of shear along this zone has been instrumental in the formation of the storm. We have also investigated the variability of cloud liquid water and water vapour mixing ratio from the third domain along $17^{\circ} \mathrm{N}$ (figure 10). This figure indicates that the regions of high water vapour in the boundary layer are also centres of convection and clouds. It may be recalled that the surface and boundary layer moisture from the model are much lower than the observations over Pune (figure 6d). The errors in low-level moisture transport would explain why the storm has not developed in the model over Pune. The model has indeed simulated an enhancement of moist static energy over the Pune region as well (see equivalent potential temperature), however, was not adequate to trigger the thunderstorm. It could be emphasised that the accurate boundary layer mixing and transport of moisture over the region will be very crucial for the prediction of thunderstorms over this region. Further detailed studies are required to address these issues. 


\section{Conclusions}

In the present study, we have analysed the characteristic features and factors contributed to the formation of a pre-monsoon thunderstorm occurred over Pune on 24 April 2011 using various co-located ground-based observations along with the WRF model. In general, synoptic conditions and analysis carried out showed that the thunderstorm considered for the study was part of the moisture convergence that developed along the dry-wet transition over the region. The main conclusions are:

1. There is a significant change in the thermodynamic indices before, during and after the development of a thunderstorm.

2. Increase in turbulent kinetic energy and moisture flux indicated pre-moistening of the lower atmosphere.

3. Strong updrafts during the storm exceeding $3 \mathrm{~ms}^{-1}$ were noticed along with the veering effect indicating significant transport of moisture. The increase in boundary layer shear during the event has sustained the storm for a longer time $(>2 \mathrm{hr})$.

4. The signature of pre-storm characteristics conducive for the storm enhancement were (i) strong cross-wind shear, (ii) convergence of moisture that originated at elevated levels in the boundary layer and (iii) enhancement of moist static energy.

5. The analysis showed that the moisture convergence along with the vertical lifting of the same has contributed to the storm intensification.

6. The comparison between the WRF model and ground observations has shown almost similar features and even model was able to recreate major features of the environment in which the storm was developed.

7. However, the model did not show triggering of a thunderstorm as noted in the observation at the same location, even with a resolution of $1.08 \mathrm{~km}$ which may be due to model bias in the moisture transport.

8. The model analysis suggested that the boundary layer mixing and transport of moisture over the region will be very crucial for the prediction of thunderstorms over this region.

Discussions presented in this study using both ground-based observations and WRF model are based on a single case of thunderstorm event. Although there are several other thunderstorm events happened over Pune, all the ground observations mentioned in this case were not in operation for all those events. Hence, the representation of results in a quantitative way explicitly using ground-based observations by involving more number of cases is difficult. This is the main limitation of the present study. Secondly, the model results presented here did not show the triggering of a thunderstorm over the study region though it could recreate the storm environment which we concluded as the inadequate low-level moisture transport. Hence, to reduce the uncertainties in the results of model, further analysis has to be carried out in future by taking more number of thunderstorm cases along with different model schemes. Sensitivity test to model schemes will be carried out in future so as to verify which scheme is more accurate in simulating the thunderstorm.

\section{Acknowledgements}

The authors are thankful to the Director, IITM and Project Director for encouragement. IITM is fully funded by the Ministry of Earth Sciences, Government of India.

\section{References}

Basu G C and Mondal D K 2002 A forecasting aspect of thundersquall over Calcutta and its parameterisation during pre-monsoon season; Mausam 53(3) 271-281.

Bhate J, Amit P K, Ananda kumar K, Bala Subrahamanyam D, Rajasekhar M, Sathiyamoorthy V and Kishtawal C M 2016 A sea breeze induced thunderstorm over an inland station over Indian South Peninsula - A case study; J. Atmos. Terr. Phys. 48 96-111.

Browning K A 1980 Review lecture: Local weather forecasting; Proc. Roy. Soc. London A 371 179-211.

Chan P W 2009 Performance and application of a multiwavelength ground based microwave radiometer in intense convective weather; Meteorol. Z. 18(3) 253-265.

Chan P W and Hon K K 2011 Application of ground based, multi-channel microwave radiometer in the nowcasting of intense convective weather through instability indices of the atmosphere; Meteorol. Z. 20(4) 431-440.

Chaudhari H S, Sawaisarje G K, Ranalkar M R and Sen P N 2010 Thunderstorms over a tropical Indian station, Minicoy: Role of vertical wind shear; J. Earth Syst. Sci. 119(5) 603-615.

Chen F and Dudhia J 2001 Coupling an advanced land surface-hydrology model with the Penn State - NCAR MM5 modeling system. Part II: Preliminary model validation; Mon. Weather Rev. 129 587-604.

Dieter R P 2014 A 10-year study on the characteristics of thunderstorms in Belgium based on cloud-to-ground lighting data; Mon. Weather Rev. 142 4839-4849, https://doi. org/10.1175/MWR-D-14-00202.1. 
Kaimal J C and Finnigan J J 1994 Atmospheric boundary layer flows: Their structure and measurement; Oxford Univ. Press, New York, 289p.

Klemp J B, Dudhia J and Hassiotis A D 2008 An upper gravity-wave absorbing layer for NWP applications; Mon. Weather Rev. 136(10) 3987-4004.

Lambert W C, Wheeler M and Roeder W 2005 Objective lightning forecasting at Kennedy Space Center and Cape Canaveral Air Force Station using cloud-to-ground lightning surveillance system data; In: AMS conference on meteorological applications of lightning data, San Diego, CA.

Leena P P, Dani K K, Nath A, Sanap S D, Pandithurai G and Anil Kumar V 2015 Validation of ground based microwave radiometer and its application in verifying atmospheric stability over Mahbubnagar during 2011 monsoon and post-monsoon season; Int. J. Remote Sens. 36 29202933.

Leena P P, Sakharam S, Anil kumar V, Das S K and Pandithurai G 2016 Characteristics of pre-monsoon convective activity over two contrasting environments from microwave radiometer data - A case study; J. Indian Geophys. Union. 20(6) 575-585.

Leslie R L, Donaldson Jr R J, Burgess D W and Brown R A 1977 Doppler radar application to severe thunderstorm study and potential real-time warning; Bull. Am. Meteorol. Soc. 58(11) 1187-1193.

Litta A J and Mohanty U C 2008 Simulation of a severe thunderstorm event during the field experiment of STORM programme 2006, using WRF-NMM model; Curr. Sci. 95(2) 204-215.

Litta A J, Mohanty U C and Idicula S M 2012 The diagnosis of severe thunderstorms with high-resolution WRF model; J. Earth Syst. Sci. 121(2) 297-316.

Madhulatha A, Rajeevan M, Venkat Ratnam M and Naidu C V 2013 Nowcasting severe convective activity over southeast India using ground based microwave radiometer observations; J. Geophys. Res.-Atmos. 118 $1-13$.

Mukhopadhayay P, Mahakur M and Singh H A K 2009 The interaction of large scale and mesoscale environment leading to formation of intense thunderstorms over Kolkata. Part I: Doppler radar and satellite observations; J. Earth Syst. Sci. 118(5) 441-466.

Patil M N, Dharmaraj T, Waghmare R T, Prabha T V and Kulkarni J R 2014 Measurements of carbon dioxide and heat fluxes during monsoon - 2011 season over rural site of India by eddy covariance technique; J. Earth Syst. Sci. 123(1) 177-185.

Pawar S D and Kamra A K 2009 Maxwell current density characteristics below isolated thunderstorms in tropics; J. Geophys. Res.-Atmos. 114, https://doi.org/10.1029/ 2008JD010348.

Pawar S D, Gopalakrishnan V, Murugavel P, Sinkevich A and Lal D M 2014 Effects of environmental conditions on inducing charge structures of thunderstorms over Eastern India; Earth Planets Space 66 54, https://doi.org/10. 1186/1880-5981-66-54.

Prabha T V, Goswami B N, Murthy B S and Kulkarni J R 2011 Nocturnal low-level jet and 'atmospheric streams' over the rain shadow region of Indian Western Ghats; Quart. J. Roy. Meteor. Soc. 137 1273-1287.
Pucik T, Groenemeijer P, Ryva D and Kolar M 2015 Proximity soundings of severe and nonsevere thunderstorms in Cenral Europe; Mon. Weather Rev. 143 4805-4821, https://doi.org/10.1175/MWR-D-15-0104.1.

Raj Ernest P, Kalapureddy M C R, Ruchith R D, Sachin Deshpande M, Sunil Sonbawne M and Dani K K 2012 Monsoon cloud and boundary layer characteristics over tropics observed with Doppler wind lidar; In: Proceedings of OCHAMP 2012.

Rajeevan M, Kesarkar A, Thampi S B, Rao T N, Radhakrishna B and Rajasekhar M 2010 Sensitivity of WRF cloud microphysics to simulations of a severe thunderstorm event over southeast India; Ann. Geophys. 28 603-619.

Rajeevan M, Madhulatha A, Rajasekhar M, Bhate J, Kesarkar A and Apparao B V 2012 Development of a perfect prognosis probabilistic model for prediction of lightning over south-east India; J. Earth Syst. Sci. 121 355-371.

Ravi N, Mohanty U C, Madan O P and Paliwal R K 1999 Forecasting of thunderstorms in the pre-monsoon season at Delhi; Meteorol. Appl. 6 29-38.

Reap R M 1994 4-hr NGM based probability and categorical forecasts of thunderstorms and severe local storms for the contiguous US; NWS Technical Procedures Bulletin No. 419, National Oceanic and Atmospheric Administration, US Department of Commerce, 14p.

Roy Bhowmik S K, Sen Roy S, Srivastava K, Mukhopadhay B, Thampi S B, Reddy Y K, Singh H, Venkateswarlu S and Adhikary S 2011 Processing of Indian Doppler weather radar data for mesoscale applications; Meteorol. Atmos. Phys. 111 133-147, https://doi.org/10.1007/ s00703-010-0120-x.

Ruchith R D, Ernest R P, Kalapureddy M C R, Sachin D M and Dani K K 2014 Time evolution of monsoon low-level jet observed over an Indian tropical station during the peak monsoon period from high-resolution Doppler wind lidar measurements; J. Geophys. Res.-Atmos., https:// doi.org/10.1002/2013JD020752.

Sen R S, Lakshmanan V, Roy Bhowmik S K and Thampi S B 2010 Doppler weather radar based nowcasting of cyclone Ogni; J. Earth Syst. Sci. 119 183-199.

Srivastava K, Roy Bhowmik S K, Sen Roy S, Thampi S B and Reddy Y K 2010 Simulation of high impact convective events over Indian region by ARPS model with assimilation of Doppler weather radar radial velocity and reflectivity; Atmosfera 23 53-73.

Suresh R 2012 Forecasting and nowcasting convective weather phenomena over southern peninsular India - Part 11: Severer local storms; Indian J. Radio Space 41 435447.

Tajbakhsh S, Ghafarian P and Sahraian F 2012 Instability indices and forecasting thunderstorms: The case of 30 April 2009; Nat. Hazard Earth Syst. 12 403-413.

Tyagi B and Vissa N K 2013 Thermodynamical structure of atmosphere during pre-monsoon thunderstorm season over Kharagpur as revealed by STORM data; Pure Appl. Geophys. 170 675-687.

Tyagi B, Satyanarayana A N V, Kumar M and Mahanti N C 2012 Surface energy and radiation budget over a tropical station: An observatory study; Asia-Pacific J. Atmos. Sci. 48(4) 411-421, https://doi.org/10.1007/ s13143-012-0037-z. 
Ulrike W and Robert G 2009 A comparison of tropical and midlatitude thunderstorm evolution in response to wind shear; J. Atmos. Sci. 66 2385-2401.

Vickers D and Mahrt L 1997 Quality control and flux sampling problems for tower and aircraft data; J. Atmos. Ocean Tech. 14 512-526.

Venkat Ratnam M, Durga Santhi Y, Rajeevan M and Vijaya Bhaskara Rao S 2013 Diurnal variability of stability indices observed using radiosonde observations over a tropical station: Comparison with microwave radiometer measurements; Atmos. Res. 124 21-33.

Corresponding editor: AsHOK KARUMURI
Weisman M L and Klemp J B 1982 The dependence of numerically simulated convective storms on vertical wind shear and buoyancy; Mon. Weather Rev. 110 504520.

Wilson J W and Mueller C K 1993 Nowcasts of thunderstorm initialisation and evolution; Wea. Forecasting $\mathbf{8}$ $113-131$.

Wilson J W, Crook N A, Mueller C K, Sun J and Dixon M 1998 Nowcasting thunderstorms: A status report; Bull. Am. Meteorol. Soc. 79 2079-2099. 